\title{
Research on Teaching Quality Supervision and Evaluation System in University
}

\author{
Bo Yang ${ }^{1, a}$ and Lina Zhang ${ }^{2, b^{*}}$ \\ ${ }^{1}$ Changchun University of Finance and Economics, Changchun, Jilin, 130122, China \\ ${ }^{2}$ Jilin Agricultural University, Changchun, Jilin, 130118, China \\ ayangbo@163.com, bhangln@163.com
}

Keywords: Education Evaluation; Teaching Quality Supervision; Index System; Platform Design

\begin{abstract}
Improving the quality of teaching is the ultimate goal of long-term pursuit. The quality of teaching is related to the social reputation and the source of students in universities, thus affecting the existence and development of such universities. This paper analyzes index system of the teaching quality supervision, and combines object-oriented technology to establish a set of efficient teaching quality supervision and evaluation platform. Through the operation of this platform, we improve and perfect the long-term mechanism for ensuring the quality of education and teaching, and help the teaching management departments of private universities to supervise and evaluate the quality of teaching reasonably and scientifically.
\end{abstract}

\section{Introduction}

Although the rapid development of private universities, but experience less hardware and software, the foundation is relatively weak, there is a big gap between the source of teachers, teaching ability, teaching infrastructure and management level, and public colleges and universities, so the quality of teaching has a larger gap. Due to the difference of school running mechanism, teacher source and teacher ability, it is difficult to evaluate the teaching quality of private colleges. It has become the focus of private universities to find teaching quality monitoring and evaluation methods suitable for private universities. How to realize the platform of quality monitoring and evaluation of teaching, the evaluation index, the evaluation process is reasonable, how to improve the utilization rate of the evaluation results, have become a major problem in monitoring and evaluation of teaching quality of private universities need to consider.

\section{The Importance of Teaching Quality Supervision and Evaluation in Universities}

The emergence of educational evaluation makes the quality of education change from qualitative cognition to objective standard and quantitative analysis. Conscientiously carry out teaching evaluation of private colleges, not only promote the construction and development of the professional, but also to build a teaching quality supervision system, promote effective [1] guarantee of college teaching quality and the overall educational level. In this case, through the establishment of a monitoring and guarantee system which is easy to maintain and improve the quality of education, the focus of the work will be shifted to strengthening teaching activities and improving the quality of education. Improve the teaching quality guarantee system, fully implement quality engineering, strengthen teaching management, improve teaching evaluation, fully mobilize the enthusiasm and initiative of students, encourage students to study hard, and develop a good style of study. The establishment of teaching quality supervision and evaluation platform for private colleges is of practical significance for improving teaching quality and improving the quality of personnel training:

$>$ To fully mobilize the initiative and enthusiasm of all the staff and students, comprehensive quality management theory emphasizes overall, to encourage all students to actively participate in, the formation of a good operation mechanism of ${ }^{[2]}$ to improve the quality of higher education.

$>$ Promote private colleges and universities to form self development, self-improvement, 
self-control, self-discipline teaching procedures, become the staff and students consciously abide by the guidelines.

$>$ Teaching and research work not only pays attention to teachers' teaching ability, but also pays attention to teachers' scientific research ability. These two abilities are constantly improved so that the quality of teaching can be improved.

\section{Index System of Supervision and Evaluation}

The index system of teaching quality supervision and evaluation in private college, is a set of quality indicators the main teaching links, directly affects the main teaching links such as preparation, classroom teaching, homework and coaching, examination, examination, such as experiment and practice, social practice and other aspects of teaching practice. The entire teaching quality and evaluation process covers all aspects of the teaching routine examination system, the teaching supervision system, the lecture system, the quality tracking system of graduates, and so on. Because of the limitation of the space, this paper takes classroom teaching and experimental teaching as an example to illustrate the indexes in the teaching quality supervision and evaluation platform. The first level index information is shown in table 1.

Table 1 first level indicator of supervision and evaluation

\begin{tabular}{|c|c|c|}
\hline number & one class index & index of 2 class \\
\hline \multirow[t]{2}{*}{1} & \multirow[t]{2}{*}{ Teaching attitude } & Teaching preparation \\
\hline & & Implementation process \\
\hline \multirow[t]{3}{*}{2} & \multirow[t]{3}{*}{ Basic teaching skills } & Teaching language \\
\hline & & Organization skills \\
\hline & & Quality cultivation \\
\hline \multirow[t]{3}{*}{3} & \multirow[t]{3}{*}{ Content of courses } & teaching material \\
\hline & & Proficiency \\
\hline & & Integrating theory with practice \\
\hline \multirow[t]{2}{*}{4} & \multirow[t]{2}{*}{ Teaching methods and means } & Adopted teaching methods \\
\hline & & Adopted means of teaching \\
\hline \multirow[t]{2}{*}{5} & \multirow[t]{2}{*}{ teaching effectiveness } & Students' abilities in all fields \\
\hline & & Student achievement \\
\hline \multirow[t]{5}{*}{6} & \multirow[t]{5}{*}{ Experimental teaching } & $\begin{array}{l}\text { Experimental teaching scheme } \\
\text { arrangement }\end{array}$ \\
\hline & & Experimental teaching preparation \\
\hline & & Laboratory equipment \\
\hline & & $\begin{array}{l}\text { Requirements and organization } \\
\text { experimental teaching }\end{array}$ \\
\hline & & Experimental general effect \\
\hline
\end{tabular}

\section{System Design and Implementation of Platform}

For the supervision and evaluation of the quality of teaching platform, the design of the system user is divided into students, teachers, teaching management, supervision department staff and super administrator, in addition to all kinds of users can be evaluated within the competence of the work, advanced users can also supervise the work of each other, the system administrator can initialize and control other users.

Students can evaluate their teaching effectiveness independently according to their own learning situation. If a student has completed the evaluation of a teaching instructor and the students' evaluation process has ended, they will not be able to evaluate it again. Supervision and peer teachers can evaluate the teaching quality and attitude of the teachers according to the situation of 
the lectures and the daily understanding of the teachers. Teaching management staff can carry out teaching quality evaluation, data statistics, summary and analysis. The administrator can perform the operation of user information, maintenance of system and initialization of information. The system design flow is shown in fig. 1 .

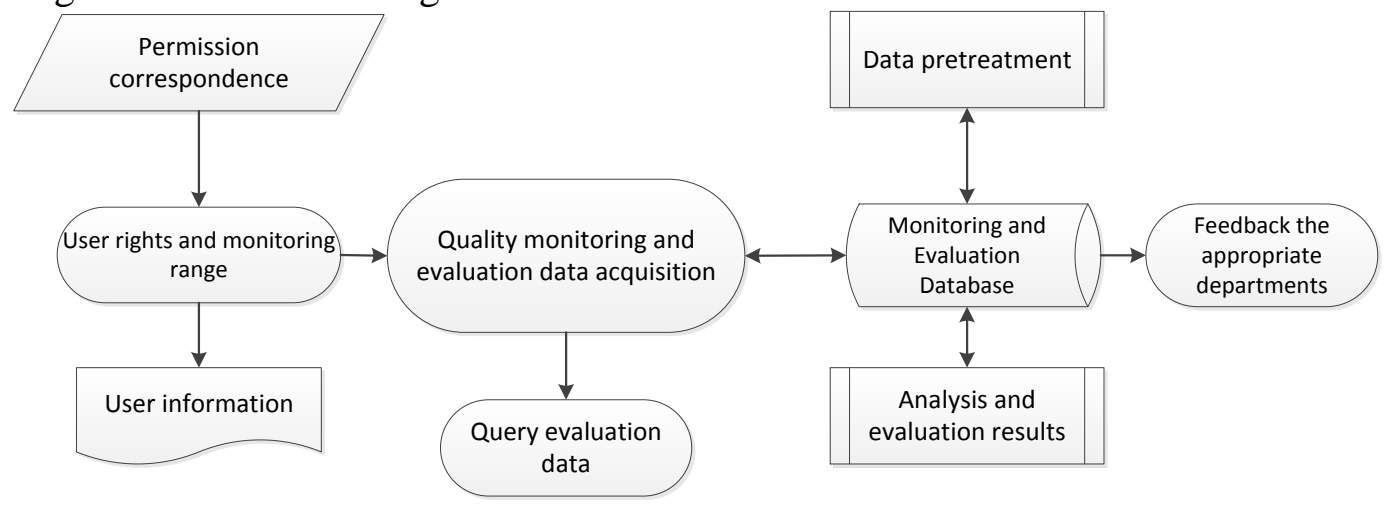

Figure1. System overall process

The system is initiated by the user first, and the number of people who use the platform is many, so it is necessary to save the user's information through the data table. The system user submits the evaluation request, the platform judges the corresponding work request according to the school teaching calendar, determines the system is in the present state, and gives the corresponding response operation according to the user request. User permissions and monitoring range is the main characteristics of the user's identity, students can only give him the teacher evaluation, and evaluation theory with only teacher's faculty or similar professional teachers, the system sets a flag, reflecting the user's monitoring and evaluation, which is particularly important. Generally speaking, it is difficult for the teachers who are not familiar with this subject to give practical and professional evaluation opinions.

In this paper, the monitoring and evaluation of teaching quality based platform and is the most important function of data acquisition, through two-way operation of evaluation information database, complete the entry and modification on the basis of the data, to ensure the normal operation of other functions effectively. The premise of data analysis is to preprocess the basic data. Through the preprocessing function, the valid data can be retained and the abnormal data can be eliminated, which plays an important role in the analysis results. The data after analysis and summarization can be fed back to the corresponding department for processing, and it can be used for query and analysis by users at all levels, thus effectively improving the utilization of data.

In this system, the index design and setting is the basis of other work. When using the platform, we must first add and modify the index system. The indexes can be set according to the demand analysis process, the indexes were not always the same, and the system provides maintenance function to modify the contents, requirements and weight, in order to meet the needs of monitoring and evaluation of teaching quality of school team development. Choose a level indicator to operate or two level indicators in the index setting function determine the index to describe the attribute name and number, describes the connotation of three levels of indicators in the notes, by adding the function of index system setting.

\section{Summary}

Teaching quality is the lifeline of survival and development. Each school should set up the teaching quality supervision and evaluation system and the corresponding data management platform according to its own development situation, so as to improve the teaching quality and the overall level of running a school. Through the data analysis, to promote the perfection and standardization of teaching management. The test proved that the private teaching quality supervision and evaluation system through the effective mobilization of evaluation personnel enthusiasm, fully play an important role in the information management system in teaching management, expand the scope 
for the evaluation of teaching quality and effectiveness, improve the utilization rate of the evaluation data, provide some decision-making support for teaching management, good application effect.

\section{Acknowledgments}

This work was financially supported by the Jilin Province Education Science "The 13th Five-year" planning issues (GH170992, ZD16038) and Jilin Provincial Institute of higher education issues in 2017(JGJX2017D308, JGJX2017C32).

\section{References}

[1] Yang Yufei, Wang Chunli. Research and Reflection on teaching quality monitoring system in private colleges [J]. Journal of Beihua University (SOCIAL SCIENCE EDITION), 2013,14 (04): 141-143.

[2] Duan Xiaohong. Research and implementation of undergraduate teaching quality monitoring platform [D]. Southwest Jiao Tong University, 2012.

[3] Yang Bo, Zhang Lina. Study on the method of intelligence analysis of the competency of teachers in private universities [J/OL]. Heilongjiang animal husbandry and veterinary medicine, 2016, (15): 263-265+299-300.

[4] Li Qiongyuan. Construction and operation of teaching quality monitoring system in private universities. Taking Nanning Institute as an example, [J]. education and teaching forum, 2013, (26): 126-128.

[5] Peter Hagell,Ellinor Edfors,Gita Hedin,Albert Westergren,Catharina Sjödahl Hammarlund. Group concept mapping for evaluation and development in nursing education[J]. Nurse Education in Practice,2016.

[6] Kathayoon Khalil,Nicole M. Ardoin,Deborah Wojcik. Social Learning within a Community of Practice: Investigating interactions about evaluation among zoo education professionals[J]. Evaluation and Program Planning,2016.

[7] Anne Felton,Nicola Wright. Simulation in mental health nurse education: The development, implementation and evaluation of an educational innovation[J]. Nurse Education in Practice, 2017.

[8] Diana R. Mager,Meredith W. Kazer,Jaclyn Conelius,Joyce Shea,Doris T. Lippman,Roben Torosyan,Kathryn Nantz. Development, Implementation and Evaluation of a Peer Review of Teaching (PRoT) Initiative in Nursing Education[J]. International Journal of Nursing Education Scholarship,2014,(1).

[9] Genevieve C. Hart,Mike Hart. Transforming South African Libraries through Leadership Education: A Programme Evaluation[J]. Libri,2014,64(4).

[10] Freida Chavez,Amy Bender,Kate Hardie,Denise Gastaldo. Becoming a Global Citizen through Nursing Education: Lessons Learned in Developing Evaluation Tools[J]. International Journal of Nursing Education Scholarship,2011,7(1). 